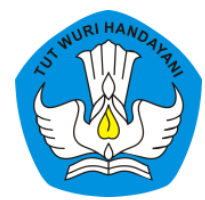

Page: 143-150

\title{
Peningkatan Minat Belajar Siswa dengan Online Remedial Teaching Menggunakan Google Drive
}

\author{
Ari Utami Nelyano \\ Sekolah Menengah Pertama Negeri 1 Tebing, Karimun, Kepulauan Riau \\ ${ }^{1}$ Contributor Email: arivia2012@gmail.com
}

Published: Mar 30, 2020

Article Url: http:/ / ojsdikdas.kemdikbud.go.id/index.php/didaktika/article/view/154

\begin{abstract}
This study aims to determine student interest in remedial learning via online at SMPN. 1 Tebing, so that students' interest in learning to participate in remidial activities is increasing. So that when there are programmed remedies, many students are absent for various reasons. As the solution of this study showed positive results, by holding Remidial Online learning turned out to be a solution how to attract students' learning interest so that they are complete in science and mathematics lessons, according to the authors of the results of this study 98\% showed students caring and responsive with online remidial learning with use Google Drive Software and Smartphone Hardware that they have. $80 \%$ of them agree that this activity is able to give them encouragement and motivation, to find out the incomplete material, indirectly build language, science and mathematics literacy in students, look for references to the material in cyberspace. Remidial online is a future learning solution that is easy to access and obtain wherever students are and is one of the complete independent learning for them to find information and transformation of knowledge they can.
\end{abstract}

Keywords: Student; Remedian; Online 


\begin{abstract}
Abstrak
Penelitian ini bertujuan untuk mengetahui minat siswa dalam pembelajaran remedial lewat online di SMPN. 1 Tebing, agar minat belajar siswa dalam mengikuti kegiatan remidial semakin meningkat, sehingga apabila diadakan remidial yang terprogram, banyak siswa yang tidak hadir dengan berbagai alasan. Sebagai solusi penelitian ini menunjukkan hasil yang positif, dengan diadakan pembelajaran Remidial Online ternyata menjadi solusi bagaimana menarik minat belajar siswa agar mereka tuntas dalam pelajaran IPA dan Matematika, yang menurut penulis dari hasil penelitian ini 98\% menujukkan siswa peduli dan tanggap dengan pembelajaran remidial online dengan menggunakan Sofware Google Drive dan Hardware Smartphone yang mereka miliki. 80\% dari mereka setuju bahwa kegiatan ini mampu memberikan mereka dorongan dan motivasi, untuk mencari tahu materi yang tidak tuntas tersebut, secara tidak langsung membangun literasi bahasa, ipa dan matematika pada peserta didik, mencari referensi materi tersebut di dunia maya. Remidial online merupakan solusi pembelajaran masa depan yang mudah di akses dan didapat dimana saja siswa berada dan merupakan salah satu pembelajaran tuntas mandiri untuk mereka mencari informasi dan transformasi ilmu yang mereka dapat.
\end{abstract}

Kata Kunci: Siswa; Remedial; Online

\title{
A. Pendahuluan
}

Peran guru di kelas sebagai fasilitator, motivator dan dinamisator pembelajaran, apalagi dalam pembelajaran IPA (Ilmu Pengetahuan Alam) yang didalamnya terintegrasi dengan 3 cabang keilmuan yaitu Fisika, Kimia dan Biologi. Sebagai fasilitator, motivator dan dinamisator guru harus mengubah pandangan belajar dari teacher centered menjadi student centered. Pandangan tersebut membuat guru berpikir bahwa dia bukan satu-satunya sumber belajar di kelas. Sumber belajar sangat banyak sekali seperti: lingkungan sekitar, alat-alat peraga, internet, buku, dan modul. Sebagai fasilitator dan dinamisator diharapkan guru berperan dalam menyediakan sumber belajar, mendampingi peserta didik dalam eksplorasi pengetahuan, memberikan umpan balik terhadap hasil belajar peserta didik, dan bersama-sama peserta didik membuat kesimpulan terhadap pembelajaran yang dilaksanakan. 
Apalagi dengan kecanggian teknologi pada siswa saat ini, seharusnya mempermudah mereka dalam penguasaan suatu pelajaran, tapi apa yang mereka lakukan?, sebaliknya dengan adanya peralatan ICT (handphone dan android) yang mereka miliki menjadikan diri mereka lepas kendali dan disibukkan dengan permainan game, pengaruh negatif, pornografi dan lainnya.

SMP Negeri 1 Tebing merupakan salah satu Sekolah yang berada di Pusat Kota Tanjung Balai Karimun, sehingga pengaruh dari lingkungan sangat mendominasi, apalagi pengaruh alat komunikasi hp android yang di miliki anak tidak bisa di kendali dengan baik, sehingga apabila razia banyak tertangkap. Hal ini juga salah satu faktor yang menyebabkan menurunnya minat belajar siswa ditandai dengan menurunnya nilai sehingga menunjukkan kualitas belajar yang menurun, sebagai solusi dalam penerapan belajar guru melakukan Remedial sebagai upaya perbaikan nilai.

Remedial membantu pemahaman anak terhadap materi yang tidak tuntas yang mereka ikuti, namun apa yang terjadi. Ketika ramidial banyak juga siswa yang tidak mengikutinya. Hal ini menyebabkan guru mencari solusi bagaimana supaya anak benar-benar mampu termotivasi belajar dan mengikuti remedial dalam perbaikan nilainya, dengan latar belakang itulah penulis coba menuangkan apa yang telah dibuat penulis dalam bentuk tulisan yang berjudul "Peningkatan Minat Belajar Siswa Dengan Online Remedial Teaching Menggunakan Google Drive".

\section{B. Metode}

Metode dalam penemuan ini saya melakukan survey secara kualitatif dengan menyebarkan angket kepada siswa pada pembelajaran IPA dan Matematika, bagaimana respon mereka terhadap pembelajaran remedial secara online. Hal ini diawali dengan problem selama ini remedial dengan jadwal dan waktu yang ditentukan sekolah. Saya 
mengambil langkah melakukan remedial secara online di rumah-rumah mereka dan dalam waktu yang kita sepakati bersama siswa.

Subhanallah, hasilnya memberikan pemahaman baru bagi kita, ternyata mampu menjadikan pengalaman baru bagi guru dan siswa dalam menjalin komunikasi group online tersebut, secara tidak langsung juga membangun literasi siswa di rumah dalam pemanfaatan Peralaatan Teknologi dan Informasi yang mereka miliki.

\section{Hasil dan Pembahasan}

Program remedial yang dilakukan dalam pembelajaran IPA dan Matematika di SMP Negeri 1 Tebing efektif dalam pelaksanaannya dengan memanfaatkan software google drive yaitu google kuiz, juga memotivasi mereka serta melatih mereka agar terbiasa menggunakan perangkat TIK yang mereka miliki. Tolak ukur keberhasilan guru maupun siswa dalam program ini dapat di lihat dari hasil angket maupun hasil penilaian remedial yang dilakukan, hasil yang di dapat sebagai berikut :
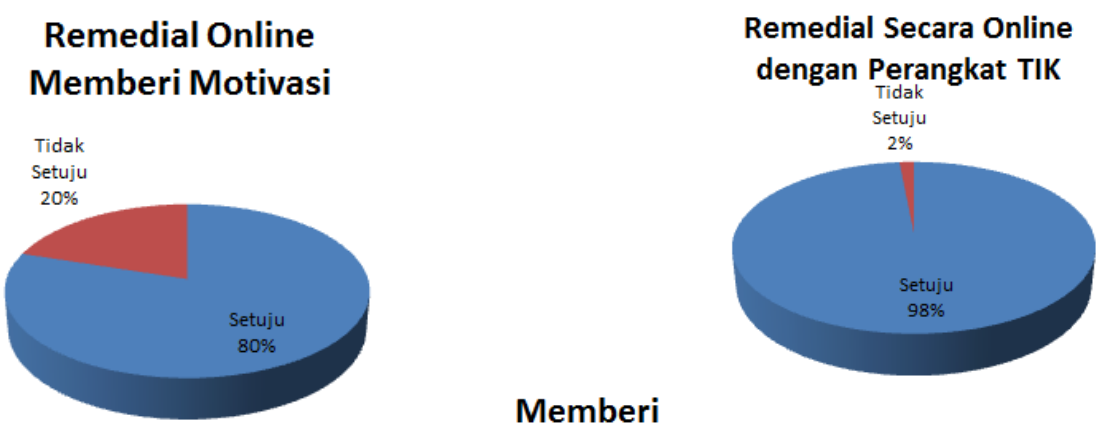

Memberi kenyamanan/tidak

Bosan bagi siswa

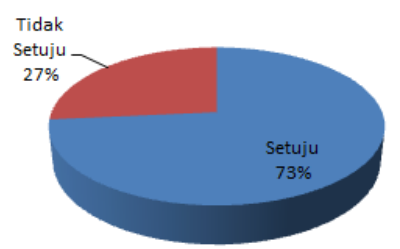




\section{Ari Utami Nelyano}

Dari hasil sebaran angket siswa untuk Remedial Online, pada pembelajaran IPA dan Matematika di dapat hasil Bahwa dari 112 siswa $(98 \%)$ sangat antusias dan setuju untuk mengikuti perubahan pola pembelajaran remedial offline menjadi Online dengan menggunakan prangkat TIK (handphone dan android), karena memberikan kemudahan akses pada mereka dan sebanyak $80 \%$ mampu memotivasi diri mereka untuk mencari tahu dari sudut mana mereka belum mengerti, sehingga membangun kemampuan literasi mereka tanpa mereka sadari. Sebesar 73\% dari hasil responden bahwa Remedial Online merupakan solusi terbaik yang Insya Allah memberikan konstribusi bagi sekolah dalam menyelesaikan ketuntasan belajar. Pembuktian dari hasil angket 100\% mereka sangat mengaharapkan pembelajaran Remedial online ini tidak hanya di pembelajaran Matematika dan IPA, Mereka sangat mengharapkan juga di Mata Pelajaran yang lain, Bahkan 97\% dari mereka sangat menginginkan kalau perlu ujian sekolah pun secara online.

Dari hasil riset menunjukkan, bahwa sudah zamannya mereka menggunakan media serba instan dan mudah dalam pembelajaran, terutama memanfaatkan teknologi jaringan dan smartphone. Untuk itu guru sudah saatnya melakukan perubahan dalam pembelajaran dengan pemanfaatan teknologi.

\section{Penutup}

1. Kesimpulan

Penelitian ini merupakan suatu upaya untuk mencari solusi tentang pembelajaran tuntas di sekolah, yang kadang menjadi suatu yang sukar dilakukan di beberapa sekolah, seperti sekolah saya. Namun saya telah berupaya mencari solusi yang membangun proses komunikasi dan 
pembelajaran siswa diluar jam pembelajaran yang merupakan pembelajaran remedial bagi siswa yang tidak tuntas. Ternyata setelah di lakukan penelitian dapat disimpulkan bahwa :

1. Penggunaan HP/Android dan Laptop pada siswa bisa digunakan sebagai media pembelajaran online yang mampu memberikan solusi dan motivasi siswa dalam pembelajaran

2. Pembelajaran Remedial online ini mampu membangkitkan literasi Bahasa, IPA dan Matematika pada siswa, karena mereka berusaha mencari pemahaman terhadap materi yang tidak tuntas.

3. Pembelajaran Remedial online adalah pembelajaran yang bisa di akses seluruh siswa yang tidak tuntas tanpa dibatasi waktu dan tempat.

4. Pembelajaran Remedial ramah lingkungan dan tanpa kertas sehingga menjadi solusi pembelajaran yang mengasikkan dalam penerapan TIK di masa mendatang

Dengan demikian pembelajaran Remedial online adalah pembelajaran tuntas untuk menyelesaikan permasalahan siswa di sekolah untuk peningkatan minat belajar siswa.

\section{Saran}

Berdasarkan hasil penerapan pembelajaran Remedial Online dapat disarankan beberapa hal :

a. Bagi Guru

- Dapat menggunakan dan menerapkan pembelajaran Remedial Online di luar jam pelajaran yang dapat mempermudah kerja guru dalam mengakses dan mendisain pola Remedial yang di lakukan 
dengan waktu dan tempat yang di atur sesuai kesepakatan dengan siswa sehingga mampu di akses siswa dimanapun berada.

- Kegiatan remedial online juga mampu memberikan pembelajaran yang kreatif, inovatif serta membangun kecakapan teknologi digital untuk peningkatan mutu dan literasi bagi guru dan siswa.

b. Bagi Masyarakat

- Merupakan pengembangan pembelajaran untuk solusi ketuntasan siswa secara mandiri dan mengembangkan pemahaman siswa dengan akses pemanfaatan teknologi informatika Komputer sehingga masyarakat tidak lagi kaku menerima perangkat android dan HP sebagai pemanfaatan pembelajaran untuk anaknya di rumah.

Juga disarankan pada penelitian akan datang bisa dilanjutkan dengan program Pemanfaatan ICT untuk ulangan mid semester dan semester, sehingga tidak lagi menggunakan kertas.

\section{Ucapan Terima Kasih}

Penulis mengucapkan Terima Kasih Kepada Ibunda Nelda Yulie, S.Pi (Ibunda Penulis) yang memberikan dukungan yang tak ternilai sehingga memotivasi selesainya karya ini, juga kepada Kesharlindung Dikdas Kementrian Pendidikan Republik Indonesia yang telah mengakui dan menilai karya tersebut sebagai Inobel pada tahun 2019, juga kepada sahabatku di MGMP IPA Rayon 1 Karimun. Alhamdulillah semoga karya ini bermanfaat. 


\section{Daftar Referensi}

Abu Ahmadi dan Widodo Supriyono, Psikologi belajar, (Jakarta: PT. Rineka Cipta, 2004).

Ependi, U. 2011. Pengertian Online, (Online), Http://blog.binadarma.ac.id/usman/wpcontent/ upload/2011/02/ pengertian- Online.pdf), diakses 28 Januari 2019.

Ischak S.W, Program remedial dalam proses belajar mengajar, (Yogyakarta: Liberty, 1982).

Mulyadi, Diagnosis Kesulitan Belajar dan Bimbingan terhadap Kesulitan Belajar Khusus (Yogyakarta: Nuha Litera, 2008).

Muna, N. R. (2014). Langkah-Langkah Penyusunan dan Pelaksanaan Evaluasi Pembelajaran.

Permatasari, A. (2014). Pengelolaan Evaluasi Hasil Belajar Peserta Didik secara Online. Jurnal Ilmu Pendidikan, 24(3), 261-264.

Suharsimi Arikunto, Pengelolaan Kelas dan Siswa, Ibid. h.67.

Sullivan, K. (2012). Pelaksanaan Evaluasi Pembelajaran. (Online), (http:// okez90.blogspot.com/2012/09/pelaksanaanevaluasipembelajaran.html), diakses 18 Maret 2014.

Tabrani ZA. (2013). Modernisasi Pengembangan Pendidikan Islam (Suatu Telaah Epistemologi Pendidikan). Serambi Tarbawi, 1(1), 65-84.

Tabrani ZA. (2014). Dasar-Dasar Metodologi Penelitian Kualitatif. Yogyakarta: Darussalam Publishing.

Wiyono, B.B. \& Sunarni. 2009. Evaluasi Program Pendidikan dan Pembelajaran. Malang: FIP Universitas Negeri Malang. 